American Journal of Applied Sciences 6 (7): 1385-1389, 2009

ISSN 1546-9239

(C) 2009 Science Publications

\title{
Physical Properties of Phenol Compound: Semi-empirical Calculation of Substituent Effects [Part One]
}

\author{
${ }^{1}$ Ammar A. Ibrahim and ${ }^{2}$ Eid A. Abdalrazaq \\ ${ }^{1}$ Department of Chemistry, College of Science, University of Mosul, Iraq \\ ${ }^{2}$ Department of Chemistry, College of Science, Al-Hussein Bin Talal University, \\ Ma'an, Jordan
}

\begin{abstract}
Problem statement: Physical properties of phenol compound such as steric energy, charge of oxygen, ionization potential, dipole moment, LUMO and bond length have been calculated. Approach: All molecular geometries were minimized by quantum mechanic especially at (AM1) method was used to investigate the effect of a variety of substituents on the phenol $(\mathrm{H}, \mathrm{o}-\mathrm{Cl}, \mathrm{p}-\mathrm{Cl}, \mathrm{m}$ $\mathrm{Cl}, \mathrm{o}-\mathrm{CH} 3, \mathrm{~m}-\mathrm{CH} 3, \mathrm{p}-\mathrm{CH} 3, \mathrm{o}-\mathrm{NH} 2, \mathrm{~m}-\mathrm{NH} 2$, o-NO2, m-NO2, p-NO2, 2,4-di-NO2). Global descriptor such as electronic chemical potential $(\mu)$, hardness $(\eta)$, the maximum electronic charge and global electrophilicity index $(\omega)$ were determined and used to predict the $(\mathrm{pKa})$ values. Results: The theoretical results (predictive values) found were in good agreement with experimental values. The predictive pKa calculated values by AM1 method gave excellent results with experimental values. The correlation between the predicted values especially global electrophilicity index showed excellent qualitative agreement with the experimental $\mathrm{pKa}(\mathrm{R} 2=0.95)$. Conclusion: The present research was to calculate the physical properties of phenol derivatives. Then, the calculated values were compared, quite favorably with experimental values of these properties. In future, we can predict any substituent of set of a phenol compound and compare its value with the experimental.
\end{abstract}

Key words: AM1, phenol, hardness, pKa, substituent effect

\section{INTRODUCTION}

Computational chemistry methods have been introduced that allow analysis of reaction mechanisms and prediction of the reactivity in synthetic chemistry. Therefore, computational chemistry is used to predict the reactivates of a wide variety of phenolic compounds ${ }^{[1,2]}$. QM methods have been successfully applied to the derivation of substituent effects of certain chemical groups in substituted phenols ${ }^{[3]}$. Quantum chemical calculations at the DFT/B3LYP, HF and AM1 and PM3 semiempirical levels were employed to calculate a set of molecular properties for 41 phenol compounds with antioxidant activity ${ }^{[4]}$. Ab initio methods (MP2 and MP4) and density function methods (BLYP and B3LYP) were used to study the effects of substitution of phenols ${ }^{[5]}$. Several kind of atomic charge of the carbons on the aromatic ring of phenol were calculated using semi-empirical and ab initio method using (RHF/3-21G), (RHF/6-31G), (RHF/6-31+G) and (B3LYP/6-311+G(2d,p) levels ${ }^{[6]}$. The substituent effect on the $\pi$-electron delocalization in aromatic moieties are often associated with a substantial intra-molecular charge transfer and the appearance of a strongly expressed quinoid structure ${ }^{[7]}$. The interaction of substituted phenol with the corn protein zein was studied on zein-coated silica and alumina stationary phases by $\mathrm{HPLC}^{[8]}$. PM3 is functionally similar to AM1, but uses an alternative parameter set. As suggested before, AM1 is also the method of choice for conformational and structural studies of phenolic molecules ${ }^{[9]}$. There are only a few theoretical studies addressing substituent effects on phenol, especially those concerning ortho-substitution. Wu and Lai used two density functional methods (LDA and BLYP) to study the effects of a number of substituents on $\mathrm{O}-\mathrm{H}$ and $\mathrm{O}-\mathrm{CH} 3$ bonds in phenols ${ }^{[10]}$. The semi-empirical (AM1) level calculation performs well in terms of its geometrical description of phenol as indicated by the close agreement with the experimental bond lengths and angles ${ }^{[11]}$.

The kinetics of the addition reactions of seven para- and meta-substituted phenols to tetramesityldisilene was studied. The resulting Hammett plot has a concave shape with a minimum for phenol, indicating a change in mechanism from a rate-determining nucleophilic step for electron-rich phenols, to a ratedetermining electrophilic step for electron-poor

Corresponding Author: Ammar A. Ibrahim, Department of Chemistry, College of Science, University of Mosul, Iraq 
phenols. Kinetic isotope effect measurements support this interpretation ${ }^{[12]}$. The reactions of $p$ dinitrobenzene and p-nitrobenzonitrile with phenolate or phenol in DMF show radical features, they can not be attributed to the direct reaction of the nucleophile on the substrate radical anion ${ }^{[13]}$. Phenolic drugs may be subject to extensive first-pass metabolism ${ }^{[14]}$. Thus, phenol was selected as a model drug substance because the metabolism has been studied extensively ${ }^{[15,16]}$. The acute toxicity of soft electrophiles such as substituted benzenes, phenols and anilines has been correlated with MNDO calculated descriptors of soft electrophilicity for aromatics: Average super delocalizability and LUMO energy ${ }^{[17]}$. Also, the AM1 calculated energy differences between the acids and their conjugate bases and the anion HOMO energies correlate satisfactorily with the experimental (condensed phase) acidity of phenols and of aromatic and aliphatic carboxylic acids $^{[18]}$.

For this view is found in a study of phenol, we are going to use AM1 method for the comparison between the experimental values of $\mathrm{pKa}$ and global electrophilicity index. Also this method is used to account for the electrophilic activation/deactivation effects. We would argue that the quantum chemical parameters described here and elsewhere provide a more flexible approach and offer a more fundamental understanding of the factors underlying the observed property variations than do empirical methodologies, such as the use of Hammett constants.

\section{MATERIALS AND METHODS}

The AM1 method has proved to be highly reliable for calculating the physical properties of molecules. The MOPAC program package, version 5.0 was used. In our semi-empirical AM1 calculations, each of these structures was used as the starting point for the energy minimization. The energy minimizations were performed until the gradient was below (Minimum RMS Gradient 0.1).

AM1 method was used to calculate the physical properties of the substituents like ionization potential (ion.pot.), LUMO energy (LUMO), bond length [R(C$\mathrm{O})$ ], oxygen charge of phenol (Charge-O) Heat of Formation (HF), total energy (total.ene.) and dipole moment. MM2 method was used to find the Steric Energy (SE) for these substituents.

Beside that, electronic chemical potential $(\mu)$, hardness $(\eta)$, the maximum electronic charge $\left(\Delta \mathrm{N}_{\max }\right)$ and global electrophilicity index $(\omega)$ parameters were been calculated. The index $(\omega)$ measures the propensity of a species accept electrons, while $\left(\Delta \mathrm{N}_{\max }\right)$ relates the electron transfer to the energy gap ${ }^{[19-21]}$.

\section{RESULTS}

The experimental $\mathrm{pKa}$ values for the substituted phenol $^{[22]}$ and Hammet constants $(\sigma)$ values ${ }^{[23,24]}$ are summarized in (Table 1), while (Table 2) shows the calculated parameters, (S.E.), (H.F.), (Total.Ene.), dipole, (ion.pot), LUMO, (Charge-O) and [R(C-N)]. All the regressions statistics for ortho, meta and para were summered in (Table 3).

Table 1: Hammett constants $(\sigma)$ and experimental $\mathrm{pK}_{\mathrm{a}}$ of phenol substituents

\begin{tabular}{llcl}
\hline Substituent & Ka & pKa & $\sigma$ \\
\hline $\mathrm{H}$ & $1.10 \mathrm{E}-10$ & 9.959 & 0.00 \\
$\mathrm{o}-\mathrm{Cl}$ & $7.70 \mathrm{E}-09$ & 8.114 & 0.20 \\
$\mathrm{p}-\mathrm{Cl}$ & $6.30 \mathrm{E}-10$ & 9.201 & 0.23 \\
$\mathrm{~m}-\mathrm{Cl}$ & $1.60 \mathrm{E}-09$ & 8.796 & 0.37 \\
$\mathrm{o}-\mathrm{CH}$ & $6.30 \mathrm{E}-11$ & 10.201 & -0.17 \\
$\mathrm{p}-\mathrm{CH}_{3}$ & $6.70 \mathrm{E}-11$ & 10.174 & -0.17 \\
$\mathrm{~m}-\mathrm{CH}_{3}$ & $9.80 \mathrm{E}-11$ & 10.009 & -0.07 \\
$\mathrm{~m}-\mathrm{NH}_{2}$ & $6.90 \mathrm{E}-09$ & 8.161 & -0.16 \\
$\mathrm{o}-\mathrm{NO}_{2}$ & $6.00 \mathrm{E}-08$ & 7.222 & 0.80 \\
$\mathrm{p}-\mathrm{NO}_{2}$ & $6.90 \mathrm{E}-08$ & 7.161 & 0.78 \\
$\mathrm{~m}-\mathrm{NO}_{2}$ & $5.00 \mathrm{E}-09$ & 8.301 & 0.71 \\
\hline
\end{tabular}

Table 2: Calculated results for substituents of phenol using AM1 method

\begin{tabular}{|c|c|c|c|c|c|c|c|c|c|c|c|c|}
\hline Substituent & $\begin{array}{l}\mathrm{HF} \\
\mathrm{Kcal}_{\mathrm{moL}}^{-1}\end{array}$ & $\begin{array}{l}\text { SE } \\
\mathrm{Kcal}_{\mathrm{moL}}{ }^{-1}\end{array}$ & Charge-O & $\begin{array}{l}\text { Tot.Ene } \\
{[\mathrm{eV}]}\end{array}$ & $\begin{array}{l}\text { Ion.Pot. } \\
{[\mathrm{eV}]}\end{array}$ & Dipole & $\begin{array}{l}\text { LUMO } \\
{[\mathrm{eV}]}\end{array}$ & $\begin{array}{l}\mathrm{R}(\mathrm{C}-\mathrm{O}) \\
\mathrm{A}^{\circ}\end{array}$ & $\mu[\mathrm{eV}]$ & $\eta[\mathrm{eV}]$ & $\omega[\mathrm{eV}]$ & $\Delta \mathrm{N}(\max )$ \\
\hline $\mathrm{H}$ & -22.32 & 0.5150 & -0.252 & -1170.94 & 9.114 & 1.233 & 0.398 & 1.3767 & -4.358 & 4.756 & 1.997 & 0.916 \\
\hline $\mathrm{o}-\mathrm{Cl}$ & -26.75 & 1.1300 & -0.236 & -1530.93 & 9.189 & 2.399 & 0.066 & 1.3751 & -4.562 & 4.628 & 2.248 & 0.986 \\
\hline $\mathrm{p}-\mathrm{Cl}$ & -29.39 & 1.0790 & -0.248 & -1531.04 & 9.124 & 1.477 & 0.095 & 1.3753 & -4.515 & 4.610 & 2.211 & 0.979 \\
\hline $\mathrm{m}-\mathrm{Cl}$ & -29.12 & 1.1430 & -0.247 & -1531.03 & 9.335 & 2.250 & 0.019 & 1.3758 & -4.658 & 4.677 & 2.320 & 0.996 \\
\hline $\mathrm{o}-\mathrm{CH}_{3}$ & -28.95 & -0.010 & -0.253 & -1326.76 & 8.964 & 0.955 & 0.396 & 1.3782 & -4.284 & 4.680 & 1.961 & 0.915 \\
\hline $\mathrm{p}-\mathrm{CH}_{3}$ & -29.87 & 0.5990 & -0.252 & -1326.80 & 8.880 & 1.360 & 0.435 & 1.3769 & -4.223 & 4.658 & 1.914 & 0.907 \\
\hline $\mathrm{m}-\mathrm{CH}_{3}$ & -29.92 & 0.6670 & -0.253 & -1362.81 & 9.041 & 1.098 & 0.378 & 1.3772 & -4.332 & 4.710 & 1.992 & 0.920 \\
\hline $\mathrm{m}-\mathrm{NH}_{2}$ & -24.18 & 5.5960 & -0.254 & -1391.98 & 8.572 & 1.580 & 0.540 & 1.3773 & -4.016 & 4.556 & 1.770 & 0.881 \\
\hline $\mathrm{o}-\mathrm{NO}_{2}$ & -15.92 & 11.334 & -0.204 & -2001.68 & 9.953 & 6.344 & -1.014 & 1.3659 & -5.568 & 4.503 & 3.442 & 1.227 \\
\hline $\mathrm{p}-\mathrm{NO}_{2}$ & -19.68 & 13.727 & -0.236 & -2001.84 & 10.071 & 5.265 & -1.065 & 1.3696 & -5.553 & 4.393 & 3.510 & 1.237 \\
\hline $\mathrm{m}-\mathrm{NO}_{2}$ & -17.56 & 23.715 & -0.240 & -2001.75 & 9.946 & 6.031 & -1.160 & 1.3750 & -4.358 & 4.756 & 1.997 & 1.264 \\
\hline
\end{tabular}


Am. J. Applied Sci., 6 (7): 1385-1389, 2009

Table 3: Correlation coefficient between all the parameters

\begin{tabular}{|c|c|c|c|c|c|c|c|c|c|c|c|c|c|c|}
\hline & $\sigma$ & $\mathrm{HF}$ & SE & Charge $(\mathrm{O})$ & ) Tot.Ene & Ion.Pot & Dipole & LUMO & $\mathrm{K}_{\mathrm{a}}$ & $\mathrm{pK}_{\mathrm{a}}$ & $\mathrm{R}(\mathrm{C}-\mathrm{N})$ & $\mu$ & $\eta$ & $\omega$ \\
\hline$\sigma$ & 1.000 & & & & & & & & & & & & & \\
\hline $\mathrm{HF}$ & 0.811 & 1.000 & & & & & & & & & & & & \\
\hline SE & 0.817 & 0.823 & 1.000 & & & & & & & & & & & \\
\hline Charge $(\mathrm{O})$ & 0.754 & 0.733 & 0.495 & 1.000 & & & & & & & & & & \\
\hline Tot.Ene & -0.953 & -0.763 & -0.872 & -0.744 & 1.000 & & & & & & & & & \\
\hline Ion.Pot & 0.970 & 0.878 & 0.884 & 0.716 & -0.950 & 1.000 & & & & & & & & \\
\hline Dipole & 0.941 & 0.896 & 0.905 & 0.800 & -0.959 & 0.966 & 1.000 & & & & & & & \\
\hline LUMO & -0.961 & -0.863 & -0.926 & -0.721 & 0.980 & -0.985 & -0.983 & 1.000 & & & & & & \\
\hline $\mathrm{k}_{\mathrm{a}}$ & 0.750 & 0.692 & 0.504 & 0.766 & -0.748 & 0.793 & 0.749 & -0.746 & 1.000 & & & & & \\
\hline $\mathrm{pK}_{\mathrm{a}}$ & -0.931 & -0.720 & -0.654 & -0.822 & 0.897 & -0.886 & -0.868 & 0.872 & -0.817 & 1.000 & & & & \\
\hline $\mathrm{R}(\mathrm{C}-\mathrm{N})$ & -0.828 & -0.753 & -0.532 & -0.926 & 0.799 & -0.810 & -0.821 & 0.786 & -0.930 & 0.869 & 1.000 & & & \\
\hline$\mu$ & -0.968 & -0.872 & -0.912 & -0.722 & 0.971 & -0.995 & -0.980 & 0.997 & -0.768 & 0.881 & 0.799 & 1.000 & & \\
\hline$\eta$ & -0.857 & -0.755 & -0.925 & -0.666 & 0.950 & -0.867 & -0.929 & 0.941 & -0.589 & 0.767 & 0.669 & 0.915 & 1.000 & \\
\hline$\omega$ & 0.956 & 0.874 & 0.929 & 0.714 & -0.973 & 0.988 & 0.983 & -0.999 & 0.753 & -0.863 & -0.786 & -0.998 & -0.9320 & 1.000 \\
\hline
\end{tabular}

\section{DISCUSSION}

Figure 1 show global electrophilicity values within the range [1.9-3.5 eV]. If we start from the unsubstituted phenol $[\omega=1.997 \mathrm{eV}]$, substitution at para position by electron donor group (p-CH3) results in an electrophilic deactivation in compound $[\omega=1.914 \mathrm{eV}]$. While substitution by the electron acceptor group (pNO2) results in a higher electrophilic activation $[\omega=3.510 \mathrm{eV}]$.

In Fig. 2, we can observe that the relationship between the (pKa) values and the global electrophilicity index shows a negative slope. This is because strongly electrophilic reagent leads to low substrate selectivity in the form of low (pKa) values.

In the case of values calculated by the AM1 method, removal of the two outlying points (m-NO2) and $(\mathrm{o}-\mathrm{Cl})$ due to increase the coefficient of determination to $(\mathrm{R} 2=0.966)$ as shown in (Fig. 3).

Comparing the experimental values with the predicted of phenol (Table 4), there is a correlation between the observed and that predicted by the AM1 method (coefficient of determination more than $\mathrm{R}=0.97)$. This clearly was shown in Fig. 4. At plotting between $(\mathrm{pKa})$ values and $(\sigma)$ values, there is only (m-NH2) outliers from these set, $(\mathrm{R}=-0.793)$. A better relationship was obtained at removing this parameter $(\mathrm{R}=-0.930)$. So, all the correlations were calculated without these parameters. The regression statistics for the performance of these parameters are given in Table 3. The correlation coefficient assumes a value between $(-1)$ and $(+1)$. If one variable tends to increase and the other decrease, the correlation coefficient is negative. Conversely, if the two variables tend to increase together the correlation coefficient is positive.

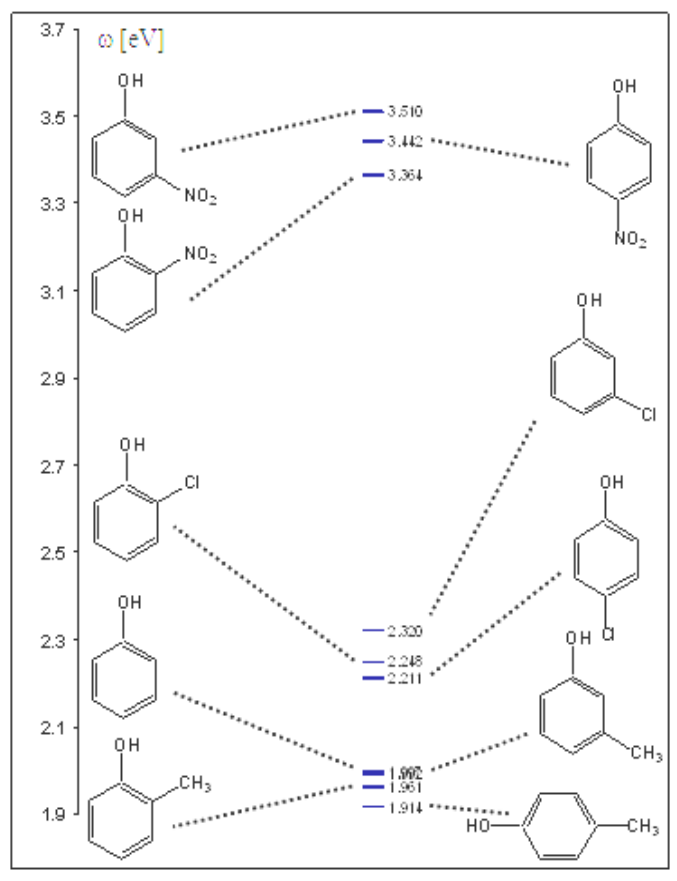

Fig. 1: Theoretical global electrophilicity index $(\omega)$

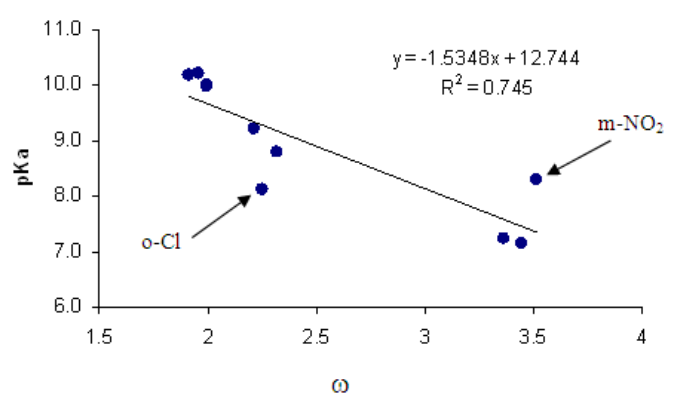

Fig. 2: Comparison between (pKa) and the global electrophilicity index 


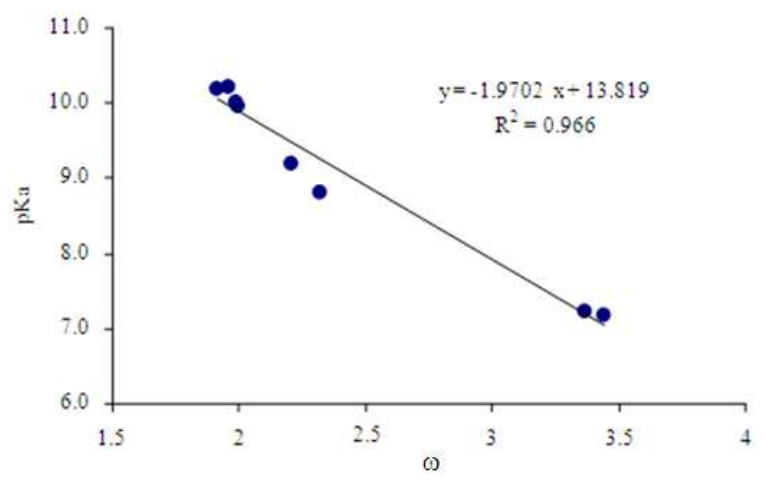

Fig. 3: Comparison between (pKa) and the global electrophilicity index after removing $\left(\mathrm{m}-\mathrm{NO}_{2}\right)$ and (o-Cl) substituents

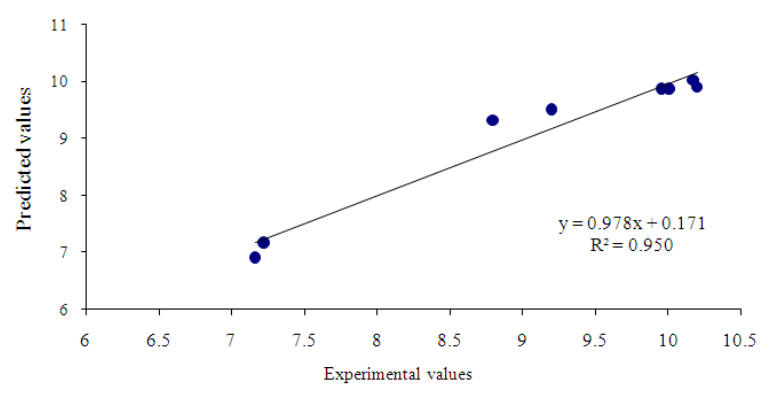

Fig. 4: The correlation between global electrophilicity index $(\omega)$ and the experimental values of $\left(\mathrm{pK}_{\mathrm{a}}\right)$

Table 4: The correlation between global electrophilicity index $(\omega)$ and the experimental values of $\left(\mathrm{pK}_{\mathrm{a}}\right)$

\begin{tabular}{llllll}
\hline $\begin{array}{l}\text { Calculated of } \\
\text { the substituent }\end{array}$ & Slope & Constant & $\mathrm{R}$ & $\begin{array}{l}\mathrm{pK}_{\mathrm{a}} \\
\text { (Experimental) }\end{array}$ & $\begin{array}{l}\mathrm{pK}_{\mathrm{a}} \\
\text { (Predicted) }\end{array}$ \\
\hline $\mathrm{H}$ & -1.957 & 13.778 & -0.981 & 9.9590 & 9.8710 \\
$\mathrm{p}-\mathrm{Cl}$ & -1.991 & 13.907 & -0.986 & 9.2010 & 9.5050 \\
$\mathrm{~m}-\mathrm{Cl}$ & -1.985 & 13.920 & -0.993 & 8.7960 & 9.3160 \\
$\mathrm{o}-\mathrm{CH}_{3}$ & -1.923 & 13.668 & -0.984 & 10.201 & 9.8970 \\
$\mathrm{p}-\mathrm{CH}_{3}$ & -1.943 & 13.735 & -0.981 & 10.174 & 10.016 \\
$\mathrm{~m}-\mathrm{CH}_{3}$ & -1.950 & 13.754 & -0.982 & 10.009 & 9.8700 \\
$\mathrm{o}-\mathrm{NO}_{2}$ & -1.990 & 13.860 & -0.973 & 7.2220 & 7.1660 \\
$\mathrm{p}-\mathrm{NO}_{2}$ & -2.064 & 14.014 & -0.974 & 7.1610 & 6.9090 \\
\hline
\end{tabular}

\section{CONCLUSION}

The theoretical methods accounts for the electrophilic activation/ deactivation effects promoted by electron withdrawing and donor substituents in these molecules. The comparison between the experimental $\left(\mathrm{pK}_{\mathrm{a}}\right)$ values and global electrophilicity index shows a linear relationship $\left(\mathrm{R}^{2}=-0.966\right)$. The values of $\left(\mathrm{pK}_{\mathrm{a}}\right)$ predicted from the knowledge of the global electrophilicity index.

\section{REFERENCES}

1. Aldersley, J.W. and P. Hope, 1972. A study of the methylolation of phenol using gel permeation chromatography Die Ang. Makromol. Chem., 24: 137-153.

http://www3.interscience.wiley.com/journal/10406 2489/abstract

2. Astarola-Aierbe, G., J.M. Echeverria, J.L. Egiburu, M. Ormaetxea and L. Mondragon, 1998. Polymer, 39: 3147-3153.

3. Zhang, H.Y., Y.M. Sun and X.L. Wang, 2002. Electronic effects on $\mathrm{O}-\mathrm{H}$ proton dissociation energies of phenolic cation radicals: A DFT study. J. Org. Chem., 67: 2709-2712. http://www.ncbi.nlm.nih.gov/pubmed/11950325

4. Mauro, R., B. Lobato, J. Lameira, A.S. Santos and C. N. Alves, 2007. A theoretical study of phenolic compounds with antioxidant properties. Eur. J. Med. Chem., 42: 440-446. http://cat.inist.fr/?aModele $=$ afficheN\&cpsidt $=1867$ 1455

5. Brinck, T., M. Haeberlein and M. Jonsson, 1997. A computational analysis of substituent effects on the $\mathrm{O}-\mathrm{H}$ bond dissociation energy in phenols: Polar versus radical effects. J. Am. Chem. Soc., 119: 4239-4244. http://cat.inist.fr/?aModele $=$ afficheN\&cpsidt $=1077$ 3672

6. Tohru, M., H.C. Anthony, G. Charles and Jr. Hill, 2002. Predicting the hydroxymethylation rate of phenols with formaldehyde by molecular orbital calculation. J. Wood Sci., 48:153-158. DOI: 10.1007/BF00767293

7. Krygowski, M.K. and B.T. Stepien, 2005. Sigmaand Pi-electron delocalization: Focus on substituent effects. Chem. Rev., 105: 3482-3512. http://www.ncbi.nlm.nih.gov/pubmed/16218559?d opt=Abstract

8. Esther, F., C. Tibor, D. Zdenek and M. Ivan, 2001. Binding of substituted phenol and aniline derivatives to the corn protein zein studied by highperformance liquid chromatography. J. Chromatogr. B., 753: 79-86. DOI: 10.1016/S03784347(00)00370-4

9. Toth, J., M. Remko and M. Nagy, 1996. Structural study of flavonoids and their protonated forms. Z. Naturforch. C: Biosci., 51: 784-790. http://cat.inist.fr/?aModele $=$ afficheN\&cpsidt $=10717468$

10. Wu, Y.D. and D.K.W. Lai, 1996. A density functional study of substituent effects on the $\mathrm{O}-\mathrm{H}$ and $\mathrm{O}-\mathrm{CH}_{3}$ bond dissociation energies in phenol and anisole. J. Org. Chem., 61: 7904-7910. http://pubs.acs.org/doi/abs/10.1021/jo960069i 
11. Dewar, M.J.S., E.G. Zoebisch, E.F. Healy and J.J. P. Stewart, 1985. AM1: A new general purpose quantum mechanical molecular model. J. Am. Chem. Soc., 107: 3902-3909. http://cat.inist.fr/?aModele $=$ afficheN\&cpsidt $=8629$ 016

12. Yitzhak, A. and M. Nakash, 1996. The mechanism of addition of phenols to tetramesityldisilene. evidence for both nucleophilic and electrophilic rate-determining steps. J. Am. Chem. Soc., 118: 9798-9799. http://www.technion.ac.il/ apeloig/papers/106.pdf

13. Jorge, M., F. Casado, M. Cervera, M. Espin, I. Gallardo, M. Mir and M. Niat, 1995. Convenient amination of weakly activated thiophenes, furans and selenophenes in aqueous media. Pure Appl. Chem., 67: 703-710.

14. Pond, S.M. and T.N. Tozer, 1984. First-pass elimination. Basic concepts and clinical consequences. Clin. Pharmacokinet, 9: 1-25. http://www.ncbi.nlm.nih.gov/pubmed/6362950

15. Ballinger, L.N., S.E. Cross and M.S. Roberts, 1995. Availability and mean transit times of phenol and its metabolites in the isolated perfused rat liver: normal and retrograde studies using tracer concentrations of phenol. J. Pharm. Pharmacol., 47: 949-956.

http://www.ncbi.nlm.nih.gov/pubmed/8708991

16. Scott, D.O. and C.E. Lunte, 1993. In vivo microdialysis sampling in the bile, blood and liver of rats to study the disposition of phenol. Pharm. Res., 10: 335-342. http://cat.inist.fr/?aModele $=$ afficheN\&cpsidt $=4658$ 044

17. Veith, G. D. and O. G. Mekenyan, 1993. A QSAR approach for estimating the aquatic toxicity of soft electrophiles. Quant. Struct.-Act. Relat., 12: 349-356. http://cat.inist.fr/?aModele $=$ afficheN\&cpsidt $=3975$ 817
18. Gruber, C. and V. Buss, 1989. Quantummechanically calculated properties for the development of quantitative structure-activity relationships (QSAR'S). pKa values of phenols and aromatic and aliphatic carboxylic acids. Chemosphere, 19: 1595-1609. http://cat.inist.fr/?aModele $=$ afficheN\&cpsidt $=6757$ 473

19. Li, S., H. Yang and Y. Jin, 2004. Lubrication chemistry viewed from DFT-based concepts and electronic structural principles. Int. J. Mol. Sci., 5: 13-34. http://www.mdpi.com/1422-0067/5/1/13

20. Utpal, S., P. Ramakrishnan, S. Venkatesan and K.C. Pratim, 2003. Effect of twist angle on calculated second order non linear responses of novel charge transfer molecular systems. Internet Elect. J. Mol. Des., 2: 000-000. http://www.biochempress.com

21. Szabo, A. and N.S. Nostlund, 1989. Modern Quantum Chemistry. 1st Edn., Dover Publication, New York.

22. Al-Hamdany, R. and M. Tawfiq, 1987. Organic Chemistry for Third Stage.1st Edn., Mosul University Press.

23. Shorter, J., 1973. Correlation Analysis in Organic Chemistry: An Introduction to Linear Free Energy Relationships, Clarendon Press, Oxford, ISBN: 0198554370 , pp: 119.

24. Hansch C., A. Leo and R.W. Taft, 1991. A survey of Hammett substituent constants and resonance and field parameters. Chem. Rev., 91: 165-195. DOI: $10.1021 / \mathrm{cr} 00002 \mathrm{a} 004$ 